\title{
Launching STEM Interst: Using Rockets to Propel to Excel in STEM Results of the Lift-Off for Teachers and Youths (LOFTY) Program
}

\author{
Reynee Kachur, Michelle Fleming, and Sara Seidling
}

Science Outreach, University of Wisconsin, Oshkosh, WI

\begin{abstract}
The Lift-Off For Teachers and Youths (LOFTY) program brought together the UW Oshkosh Science Outreach Program within the College of Letters and Science and College of Education and Human Services faculty to provide a space-related science learning opportunity for inservice teachers that in turn excites and engages the students they teach in aerospace-related science, design and technology. This project dovetailed nicely with many of the other hands-on science programs already conducted by Science Outreach, while at the same time filling a void of increasing the content knowledge of elementary teachers, and increasing the interest and hands-on space-related science experiences for elementary students in Wisconsin. The LOFTY project also emphasized current NASA education goals including helping educators and students develop the critical skills and knowledge base in space-related science. By bringing in elements of an in-service hands-on teacher training, cross disciplinary discussions to incorporate a rocket unit into each subject, planetarium shows at the Buckstaff Planetarium, and using the framework of the Science Olympiad rules and values, the LOFTY project increased interest in and excitement for science, technology, engineering and mathematics (STEM).
\end{abstract}

\section{Introduction}

UW Oshkosh is a state-assisted, non-profit institution of higher education. Its mission is to provide undergraduate, select graduate and continuing/professional education opportunities, engage in research and other scholarly activity, and serve as a regional educational, cultural, and economic development resource. The University of Wisconsin Oshkosh and the project leaders have several strengths relevant to this proposal.

First, the Science Outreach Program, housed at the University of Wisconsin Oshkosh (UW Oshkosh), is devoted to making science education accessible, exciting, and up-to-date to students, teachers, and the community, by expelling misconceptions through hands-on experiences and by supporting the University's mission. Throughout the school year, Science Outreach hosts a variety of preK-12th grade groups on the UW Oshkosh campus for learning programs in college science labs, and also visits local elementary, middle, and high schools to provide educational programs on location. In addition, Science Outreach has a long tradition of providing high quality, content-rich summer science workshops for in-service teachers (including: Operation Chemistry, SUMmer Science Workshop (SUMS), and Children's Literature and Science Project (CLASP), and Science Teaching through Universal Design and Inquiry (STUDI) programs).

Science Outreach also runs the Buckstaff Planetarium located on campus and provides astronomy and planetarium shows for UW Oshkosh students and the community. Science Outreach strives to develop and deliver educational and informational planetarium shows in the Buckstaff Planetarium, while maintaining a smaller, informal atmosphere that encourages 
interaction between our show presenters and the audience. We believe this focus provides a greater astronomy learning experience for all ages in the audience.

In addition, Science Outreach also hosts the Wisconsin Division B Middle School Science Olympiad competition. Every year, nearly 40 middle school teams from around the state compete in 23 events during the state Science Olympiad competition held at UW Oshkosh. Science Olympiad combines events from all disciplines to encourage a wide cross-section of students to get involved, plus the events reflect the ever-changing nature of science. Each year, at least one event is devoted to astronomy and space-science. In 2011, one of the astronomy events is called Bottle Rocket, in which competitors design and build a bottle (water) rocket with the goal of keeping their rocket up in the air the longest. This event requires a combination of knowledge about space-science, technology and mathematics.

Second, UW Oshkosh has one of the top programs in the state for educating teachers. Recent innovations include alternative licensure programs such as Alternative Careers in Teaching (ACT) to recruit and train more teachers in the areas of science, technology, engineering and mathematics. Under the leadership of Dr. Michael Beeth, this program has attracted major support from the National Science Foundation. Science Education was also prioritized by UW Oshkosh in its recent Growth Agenda, making it possible to hire more faculty. These new hires include Dr. Michelle Fleming, who has built up new capacities for the university, including organization and recruitment of a large student chapter of the National Science Teachers Association (NSTA).

Through this project the successful elements of programs offered by Science Outreach and the elementary educational leadership of Michelle Fleming were combined to provide a spacerelated science learning opportunity for in-service teachers, that in turn excites and engages the students they teach in aerospace-related science, design and technology. By bringing in elements of an in-service hands-on teacher training, cross disciplinary discussions to incorporate a rocket unit into each subject, planetarium shows at the Buckstaff Planetarium, and using the framework of the Science Olympiad rules and values, the overarching goal of the LOFTY program was to increase interest in and the love for science, technology, engineering and mathematics (STEM).

\section{Program Details}

In a two-day workshop (two 7-hour days) held on Saturday, September $24^{\text {th }}$ and October $8^{\text {th }}$, 2012, seven elementary teachers came to the UW Oshkosh campus to learn the science concepts behind the design and construction of bottle (water) rockets through problem solving, hands-on, minds-on constructivist learning practices. The schedule and activities selected for this workshop were chosen to help these elementary teachers learn rocketry fundaments, to be able to incorporate the lessons into their current classroom curriculum, to help their students learn the principles of rocket engineering, to employ the scientific method to design and construct a bottle rocket, and to test student built rockets at their school.

During both sessions with the in-service teachers, an emphasis was placed on discipline crossover to allow teachers to spend more time discussing science. Examples of cross-discipline ideas shared during the LOFTY session included: fiction and non-fiction books for use during reading, review of a science notebook for writing, accounting and measurements for math. Each 
participant was charged with coming up with additional ways to blend science with other subjects taught throughout the day to increase student thinking about science outside of a true science class. By interweaving science throughout the day and in several subjects, these $4^{\text {th }}$ and $5^{\text {th }}$ grade teachers can make science less intimidating for students and build student confidence in science disciplines.

A major focus on both workshop days was the concept of an interactive science notebook, or a student learning tool that records both the content learned and the reflective knowledge gained (Marcarelli, 2010). A science notebook allows the students to "become" scientists and record all their experimental data, notes, results, and interpretations of the results in one place, just as a true scientist would. In addition to teacher-led discussions (content), one aspect of the science notebook is to have students reflect, assess, and make connections which provide important insights into student understanding, misconceptions, and can serve as a formative assessment tool (Hargroove \& Nesbit, 2003; Gilbert \& Kotelman, 2005). Some of the "key ideas" and reasons to try a science notebook in a classroom were shared with the participants and included:

Key Ideas: How Notebooks Promote Learning:

- Interactive journaling will make a $\bullet$ Improve organization skills difference!

- A concrete record of reflection,

- Students are actively engaged in thinking and communicating. assessment, and connections

- Improve critical thinking skills

- Students feel "ownership" because they are creating meaningful knowledge for themselves.

- There's no "right" or "wrong" way.

- Modify to find ways that work best for you and your students.

- Express understanding creatively

- Connect student thinking and experiences with science concepts

- Engage students

- Provide opportunities for all students

During the two days of LOFTY, participants experienced a wide variety of aerospace activities and/or lesson plan ideas that they could take back to their school (each teacher was given copies of the curriculum to incorporate building rockets into their current $4^{\text {th }}$ or $5^{\text {th }}$ grade curriculum). An outline of the participant topic/schedule is provided in Table 1. The culminating event was a Bottle Rocket competition based on the 2011 Division B Science Olympiad Bottle Rocket event rules. Participants constructed and launched two rockets in a mock competition. This activity better prepared these teachers to help their own students understand and construct bottle rockets during the school year. Asking the participants to go through the building process during the training prepared them for the materials students would need, and the ideas and misconceptions students might experience. Throughout each activity or lesson, participants were asked to use a science notebook to reinforce the science notebooking concepts and to model the practice. Participants could then take the parts of the science notebook that worked best for them and incorporate those ideas into their classroom as well.

For their participation in the LOFTY project, the participants were provided with a bottle (water) rocket launcher. By providing the launchers, teachers in the school/district now have easy access to the equipment in order to continue to teach the rocket unit beyond the life of this grant. In addition, upon completion of the requirements of the LOFTY project (participating in the 
workshop, teaching a rocket unit in their classrooms during the 2011-2012 school year, and writing a reflection paper), each participant received one graduate credit from the UW Oshkosh College of Letters and Science.

Table 1: Schedule of the 2011 LOFTY Summer Workshop for 4th and 5th grade teachers.

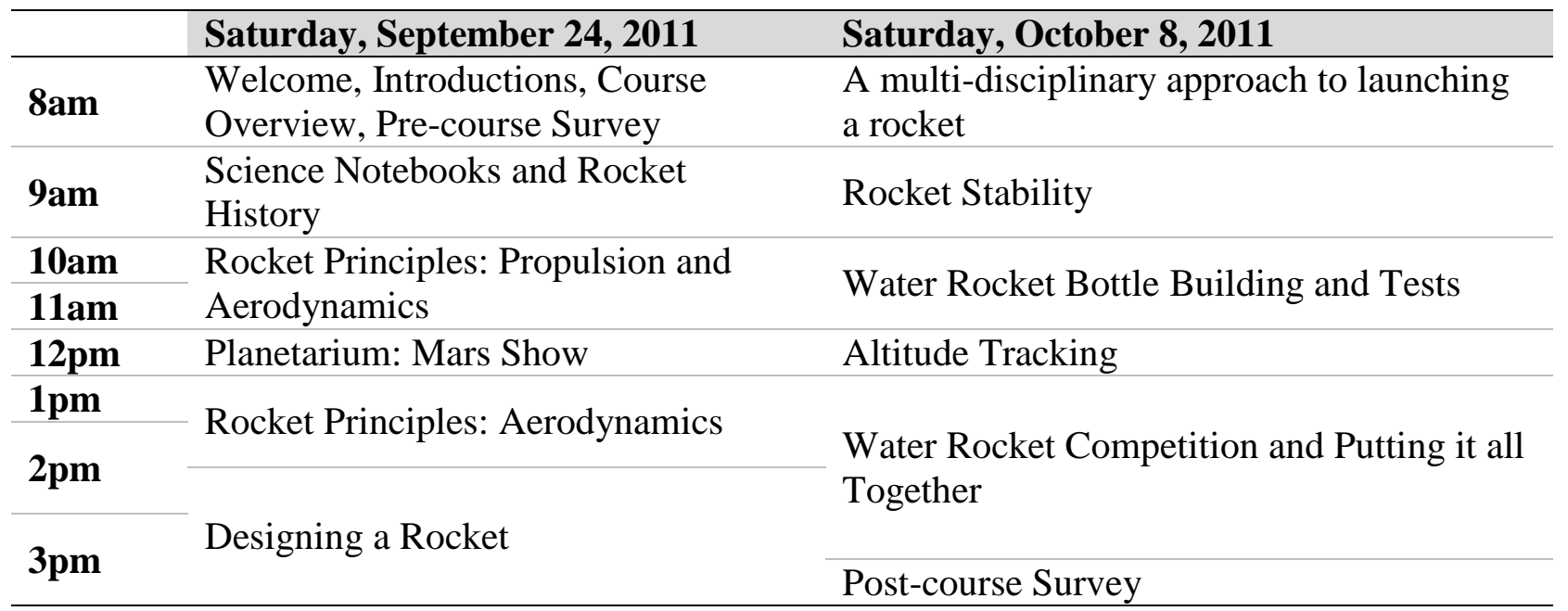

\section{Results}

Participant pre- and post-test questions on science content knowledge, understanding of the scientific process, and ability to incorporate the rocket-science activities, lessons, and ideas into existing curriculum (i.e., multiple choice, short answer, and Likert scale questions) were administered as part of this program as one indicator of participant learning. Overall, participants showed a positive change in science knowledge on the pre- versus the post-test on rocket and flight concepts. For specific rocket content such as the parts of a rocket, there was an increase in ability to correctly identify the various parts of a rocket (nose, fins, cone). For example, only $40 \%$ of the participants when pre-assessed correctly identified the nose cone of a rocket, whereas $60 \%$ of the participants post-workshop gave the correct response; and $50 \%$ correctly identified the nozzle portion of the rocket on the pre-test, but all participants correctly identified the nozzle post-workshop. In addition, more participants were able to correctly identify how to stabilize a rocket on the post-assessment (pre-workshop only 3 participants correctly identified, post-workshop this increased to 7 participants). With an improved rocket science knowledge base, teachers had an increased comfort level teaching rocketry principles in their science classes, enhanced their confidence in teaching science concepts (pre: $M=2.78$, $\mathrm{SD}=0.44$; post: $\mathrm{M}=3.33, \mathrm{SD}=0.71 ; \mathrm{p}=0.013$ ) and in particular teaching rocketry principles in science classes (pre: $\mathrm{M}=2.11, \mathrm{SD}=1.05$, post: $\mathrm{M}=3.39, \mathrm{SD}=0.60 ; \mathrm{p}=0.002$ ), and gained confidence in their own skills and abilities to teach science (pre: $\mathrm{M}=2.50, \mathrm{SD}=0.71$, post: $\mathrm{M}=2.00, \mathrm{SD}=0.71 ; \mathrm{p}=0.005)$.

As another measure of the success of the LOFTY program, participants were asked to evaluate changes in student content knowledge and student understanding of the scientific process quantitatively through a method outlined in the aeronautics unit (i.e. pre- and post-tests), and student change in attitudes and beliefs towards science and STEM disciplines during the unit. All student data was provided without student identifiers and only as the raw score for pre- 
versus post-test assessment. Across all participants, nearly all students had an increase in content knowledge (based on pre- and post-test scores on the participant created/adapted rocketry unit). In particular, one participant saw at minimum of a $20 \%$ increase in each student's score from the pre- to the post- assessment. In addition, many students experienced a change in attitude toward science. All of the participants qualitatively reported an increase in student enjoyment of science after the rocket unit, and enjoyed the hands-on activity of creating a rocket:

"The main thing students liked was creating, making something, having a hands-on experience in science. Many students seemed almost surprised that they had enjoyed the science unit. They said in the past science had been worksheets and packets and they didn't like science very much. They told me they hoped we would continue to do more hands-on activities for the rest of the year."

In addition, students reported using technology (computers or graphic calculators) more after the unit (pre: $\mathrm{M}=2.17, \mathrm{SD}=1.30$; post: $\mathrm{M}=3.39, \mathrm{SD}=0.99 ; \mathrm{p}=0.001$ ), and saw connections between science and other classes (pre: $\mathrm{M}=2.65, \mathrm{SD}=0.93$; post: $\mathrm{M}=3.39, \mathrm{SD}=0.66 ; \mathrm{p}=0.004$ ).

\section{Conclusion}

By integrating a space-related science unit into $4^{\text {th }}$ and $5^{\text {th }}$ grade classrooms, students become actively engaged in science at a young age. Creating a bottle (water) rocket allows these students to practice the scientific method, learn science in a hands-on way, use engineering and mathematic skills, and to express their creativity. A cross-discipline approach to science through the use of science notebooks, and incorporating a unified theme through all the subjects (history, art, math, social studies) provides students greater exposure to science, makes connections between science and other disciplines, and increases student comfort level with science. By given teachers lessons and activities and having the teachers go through each lesson or activity, teachers learn the content, build their own confidence level with the content, and are better able to help students understand the material and teach students to solve problems through real-world applications of the scientific method. All this, while having fun building a bottle rocket.

The underlying theme behind the student attitude survey results was that past experiences (good and bad) in science have shaped student ideas about science. In order to change those ideas and to show students how science relates to the world around them, it takes a hands-on, crossdisciplinary unit that students can become actively and creatively involved in. Showing students that science learning can overlap into other subjects through cross-disciplinary teaching, creates a greater appreciation and love for science.

Overall, the best part of the LOFTY project was the teacher's enthusiasm which carried over into the classroom. Nearly all participants qualitatively indicated that their students were engaged, excited, and interested in the rocketry unit. In many cases, students in older grade levels who did not get to participate in creating a rocket were upset that their younger counterparts now got the opportunity to do so; while students in the younger grade levels were asking the teachers when they would get to make the rockets. Beyond the impact to the students, even teachers within the same building/district are asking the LOFTY participants to share their rocketry units.

The inquiry, hands-on, science based learning opportunities provided by the LOFTY program not only enriched current in-service teachers' curriculum, but enhanced students' scientific 
learning. Through this experience, participants improved their ability to integrate building bottle rockets into their curriculum and confidently answer questions about rockets. This hands-on, real-world application approach to learning space-related science enabled students to experience how science works, generated excitement about science and rockets, and built confidence in science and mathematics skills. Thus, this project helped students enjoy science classes and to develop positive skills in science that will last a lifetime.

\section{References}

Gilbert J., and Kotelman, M. (2005, December). Five good reasons to use science notebooks. Science \& Children, 43(3), 28-32

Hargroove, T., and Nesbit, C. (2003). Science notebooks: Tools for increasing achievement across the curriculum. (ERIC Document Reproduction Service No. ED482720). Retrieved January 10, 2012, from http://www.ericdigests.org/2004-4/notebooks.htm.

Marcarelli, K. (2010). Teaching Science With Interactive Notebooks. Thousand Oaks, CA: Corwin. 